\title{
A Rare Case of Undeveloped Multiple Pregnancy in Uterus Didelphys
}

\author{
Slavchev $\mathrm{S}^{1}$, Yordanov $\mathrm{A}^{2 *}$, Donkov $\mathrm{V}^{1}$, Vasileva $\mathrm{P}^{3}$ and Malkodanski $\mathbf{I}^{4}$ \\ ${ }^{1}$ Clinic of gynecology, MHAT "St. Anna”, Bulgaria \\ ${ }^{2}$ Clinic of Gynecologic Oncology, University Hospital, Bulgaria \\ ${ }^{3}$ Department of Obstetrics and Gynecology, Medical University, Bulgaria \\ ${ }^{4}$ Department of Critical care, Medical University, Bulgaria
}

Submission: October 24, 2017; Published: November 10, 2017

*Corresponding author: Angel Yordanov, Clinic of Gynecologic Oncology, University Hospital “Dr. Georgi Stranski”-Pleven, Bulgaria, Europe, Tel: 359887 671520; Email: angel.jordanov@gmail.com

\begin{abstract}
Uterus anomalies result from an abnormal development of the Mullerian ducts during embryogenesis and are a diverse group of malformations. Their incidence in the general population is $4.3 \%$. Uterus didelphys is a relatively rare uterus abnormality. It's related to the reduced ability of conception, higher incidence of abortions, premature birth, abnormal fetus position and presentation and cesarean section. We present a very rare case of spontaneous and undeveloped multiple pregnancies in each of the uteruses of uterus didelphys. We diagnosed this malformation with the help of transvaginal ultrasound test. We performed vacuum aspiration separately for each of the uterine cavities.
\end{abstract}

Keywords: Uterus Didelphys; Multiple Pregnancy; Outcome

\section{Introduction}

Müllerian ducts anomalies are congenital defects of the female reproductive system and are a diverse group. Their incidence in the general population is around $4.3 \%$, and in patients with recurrent miscarriages is up to $13 \%$ [1]. The most common anomaly is a septate uterus in 35\% of cases, followed by unicornuate uterus in $25 \%$ of cases and arcuate uterus in $20 \%$. Uterus didelphys is among the most rare uterine anomalies, with 1 of $1000-30000$ women and a share of $8.2 \%$ [1]. This malformation, as the other abnormalities in the uterus development is related to various obstetrical problems - secondary sterility and premature pregnancy termination. Multiple pregnancy in case of uterus didelphys is a very rare condition.

\section{Clinical Case}

It is about a 20 year old patient, who is sent to the clinic for termination of the found undeveloping multiple pregnancy. The ambulatory gynecology examination showed two separate uteruses, and in each of them was visualised a gestational sac with one embryo, fitting 7-8 gestational week and lack of heart pulsations. The patient's symptomes were weak genital bleeding, with no pain syndrome. That fit the clinical presentation of a missed abortion. Our gynecology examination showed the presence of a longitudinal septum of the vagina around $3 \mathrm{~cm}$ and to the left and right of it-two separate uterine cervixes. Transvaginal ultrasonography visualised two gestational sacs with two embryos, without heart activity, localized in two separate uterine cavities (Figure 1). The two uteruses were fitting for the amenorrhea duration - 7-8 $8^{\text {th }}$ gestational week. We diagnosed uterus didephys with missed abortion of two embryos in two separate gestational sacs, each of them localized in a separate uterine cavity.

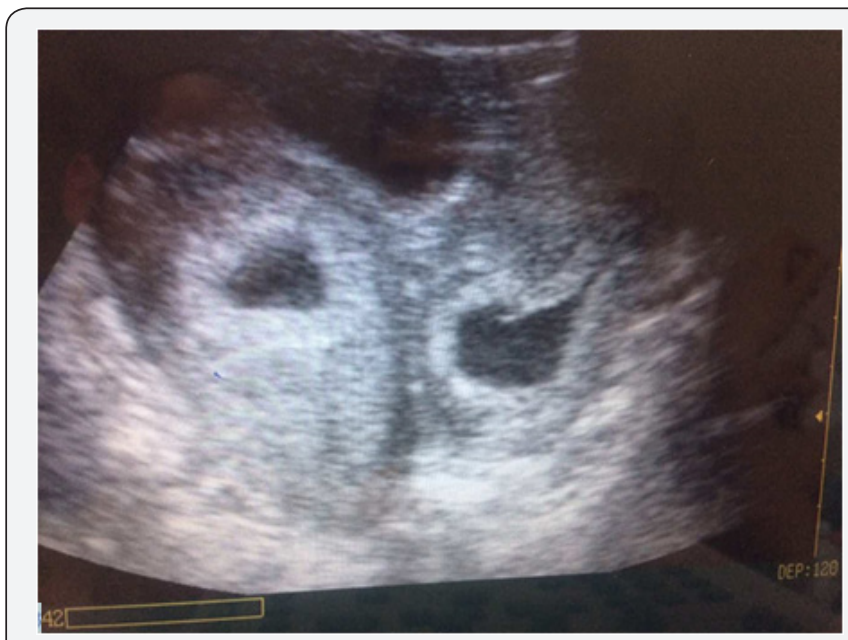

Figure 1: Transvaginal ultrasonography - two separate uteruses, in each of them a gestational sac is found with one embryo. 
Patient has no complaints of pelvic discomfort and the anomaly was found accidentally, in relation to the pregnancy. We performed dilatation and curettage (vacuum aspiration) consecutively for both uteruses, and we measured the depth up to $8 \mathrm{~cm}$ and dilated up to Hegar $10.5 \mathrm{~mm}$. The manipulation was not easy, since the woman hadn't given birth and the two cervical canals were closed. Post-procedure there was fever up to 38 degrees $\mathrm{C}$ and pain in the lower part of the abdomen, handled with antibiotic treatment for 5 days. Currently the patient is pregnant again, in 5th lunar month, with one embryo 8 months after this case.

\section{Discussion}

Uterus didelphys is an anomaly in the development of the female reproductive system. The reason is the failed merging of the two Müllerian ducts in 8th gestational week of the embryonic development, which leads to complete duplication of the reproductive structures [2]. Usually the duplication is limited to the uterus and the cervix, but sometimes duplications of the vulva, vagina, bladder, urethra and anus can be seen. The anomaly is placed in class III of the classification of the American Fertility Society [3]. It is the presence of two uteruses, which are almost normal-sized, two uterine cervixes, and out of each of the uteruses exits one Fallopian tube [4]. In 15-20\% of the cases an unisided renal agenesis may be present (usually right-sided) [5]. Accompanying anomalies are explained with the simultaneous embryonic development of the mesonephric and Müllerian ducts. In $75 \%$ of cases the vagina is also septate, which can be a reason for complications during vaginal birth or during sexual intercourse [2].

Most sources report the incidence for uterus didelphys between $0.5 \%$ and $5 \%$ of general population and it is $8.2 \%$ of the uterine anomalies [1,6-8]. Most commonly the anomaly is asymptomatic and is found accidentally, which is probably a reason for the inacurate evaluation of the incidence. Clinically it can present itself with pelvic discomfort, dyspareunia, dysmenorrhea, hematocolpos and hematometra [9]. The possibility for conception is not impaired and happens in $74 \%$ of patients, but pregnancies do not go seamlessly - there are miscarriages in $32.9 \%$ of cases, premature birth in $28.9 \%$, birth on term in $36.2 \%$ and birth of a living child in $56.6 \%$. The incidence of the breech position, cesarean section delivery and fetal retardation is higher [6]. There is insufficient information about the multiple pregnancy, because of its extremely low incidence - 1 in 1 million pregnancies [10]. There are separate publications about a spontaneous multiple pregnancy in the separate uterine cavities, like in the presented case [10-15]. Diagnosing congenital anomalies of the female reproductive system begins with ultrasound examination, and with better differentiating ability of the structures are the transvaginal ultrasonography and the 3D echography. Other methods include hysterosalpingography, laparoscopy and laparotomy. MRI has the advantage of being non-invasive technology, and for finding accompanying renal anomalies.

\section{Conclusion}

A very rare case of a spontaneous pregnancy is presented, with two embryos in each of the uteruses in the case of uterus didelphys. Uterine anomalies are with higher risk of abortion. In case of a missed abortion there is a high risk of complications of the surgical procedure, due to the changed anatomy.

\section{References}

1. Grimbizis GF, Camus M, Tarlatzis BC, Bontis JN, Devroey P (2001) Clinical implications of uterine malformations and hysteroscopic treatment results. Human Reproduction Update 7(2): 161-174.

2. Iverson RE, DeCherney AH, Laufer MR (2017) Clinical manifestations and diagnosis of congenital anomalies of the uterus. Up to Date, Wolters Kluwer 2017.

3. (1988) The American Fertility Society classifications of adnexal adhesions, distal tubal occlusion, tubal occlusion secondary to tubal ligation, tubal pregnancies, müllerian anomalies and intrauterine adhesions. FertilSteril 49: 944.

4. Chandler TM, Machan LS, Cooperberg PL, Harris AC, Chang SD (2009) Müllerian duct anomalies: from diagnosis to intervention. The British Journal of Radiology 82(984): 1034-1042.

5. Vercellini P, Daguati R, Somigliana E (2007) Asymmetric lateral distribution of obstructed hemivagina and renal agenesis in women with uterus didelphys: institutional case series and a systematic literature review. Fertil Steril 87: 719.

6. Heinonen PK (1984) Uterus didelphys: a report of 26 cases. European Journal of Obstetrics and Gynecology and Reproductive Biology 17(5): 345-350.

7. Heinonen PK (2000) Clinical implications of the didelphic uterus: longterm follow-up of 49 cases. European Journal of Obstetrics and Gynecology and Reproductive Biology 91(2): 183-190.

8. Raga F, Bauset C, Remohi J, Bonilla-Musoles F, Simon C, et al (1997) Reproductive impact of congenital Mullerian anomalies. Human Reproduction 12(10): 2277-2281.

9. Rezai Sh, Bisram P, Alcantara IL (2015) Didelphys Uterus: A Case Report and Review of the Literature. Case Reports in Obstetrics and Gynecology.

10. Nohara M, Nakayama M, Masamoto H, Nakazato K, Sakumoto K, et al. (2003) Twin pregnancy in each half of a uterus didelphys with a delivery interval of 66 days. BJOG 110(3): 331-332.

11. Díaz-García C, Subirá Nadal JP, Urgal Ayala A, CazorlaAmorós E, BorrásSuñer D, et al. (2010) Spontaneous triplet pregnancy complicated by uterus didelphys: a case report. Fetal Diagn Ther 27: 227-230.

12. Hochner-Celnikier D, Yagel S, Beller U, Milwidsky A (1983) Simultaneous pregnancy in each cavity of a double uterus. A case report. Int ] Gynaecol Obstet 21: 51-53.

13. Hua M, Odibo AO, Longman RE, Macones GA, Roehl KA, et al. (2011) Congenital uterine anomalies and adverse pregnancy outcomes. Am J Obstet Gynecol 205: 1-5.

14. Leiberman JR, Schuster M, Piura B, Chaim W, Cohen A (1980) Mullerian malformations and simultaneous pregnancies in didelphys uteri. Review and report of a case. Acta Obstet Gynecol Scand 59: 89-91.

15. Ozyuncu O, Turgal M, Yazicioglu A (2013) Spontaneous twin gestation in each horn of uterus didelphys complicated with unilateral preterm labor. Case Reports in Perinatal Medicine 3(1): 53-56. 
This work is licensed under Creative Commons Attribution 4.0 Licens DOI: 10.19080/OAJS.2017.06.555695

\section{Your next submission with Juniper Publishers} will reach you the below assets

- Quality Editorial service

- Swift Peer Review

- Reprints availability

- E-prints Service

- Manuscript Podcast for convenient understanding

- Global attainment for your research

- Manuscript accessibility in different formats

( Pdf, E-pub, Full Text, Audio)

- Unceasing customer service

Track the below URL for one-step submission https://juniperpublishers.com/online-submission.php 